\title{
Sensitive Superoxide Detection in Vascular Cells by the New Chemiluminescence Dye L-012
}

\author{
Hae-Young Sohn ${ }^{a}$ Torsten Gloe ${ }^{a}$ Matthias Keller ${ }^{a}$ Karl Schoenafinger ${ }^{b}$ \\ Ulrich Pohla

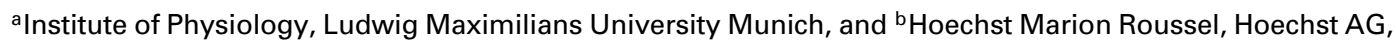 \\ Frankfurt, Germany
}

\section{Key Words}

Superoxide $\cdot \mathrm{L}-012 \cdot$ Chemiluminescence Endothelium, physiology · Vanadates - NADPH oxidase - Tyrosine phosphatases

\begin{abstract}
The detection superoxide production in vascular cells is usually limited by a low sensitivity of available assays. We tested the applicability of the luminol derivate L-012 [8-amino-5-chloro-7-phenylpyridol[3,4-d]pyridazine-1,4(2H,3H)dione] to measure superoxide production in cultured endothelial cells (human umbilical vein endothelial cells) and rat aortic segments. Following stimulation with the protein kinase stimulator phorbol 12-myristate 13-acetate (PMA, $1 \mu M$ ) there was an 2.8-fold increase of L-012 chemiluminescence, whereas incubation with angiotensin II $(100 \mathrm{nM})$ did not result in a measurable increase. Addition of vanadate $(100 \mu M)$ considerably increased the chemiluminescence (up to 17-fold) after PMA and made possible the detection of an enhanced superoxide production after stimulation with angiotensin II (by 1.7-fold). This was due to a $\sim 9$-fold increase in signal intensity of L-012 in the presence of van-
\end{abstract}

\begin{tabular}{ll}
\hline KARGER & ( 1999 S. Karger AG, Basel \\
1018-1172/99/0366-0456\$17.50/0 \\
$\begin{array}{l}\text { Fax +4161306 1234 } \\
\begin{array}{l}\text { E-Mail karger@karger.ch } \\
\text { www.karger.com }\end{array}\end{array}$ & $\begin{array}{l}\text { Accessible online at: } \\
\text { www.karger.com/journals/jvr }\end{array}$
\end{tabular}

adate. Prolonged incubation with vanadate also led to a tyrosine phosphorylation-dependent increase in superoxide formation which was predominantly produced by an $\mathrm{NAD}(\mathrm{P}) \mathrm{H}$ oxidase. Short-term vanadate-enhanced L-012 chemiluminescence represents a highly sensitive assay making it possible to detect small changes of superoxide formation in intact vascular cells.

Copyright $\odot 1999$ S. Karger AG, Basel

\section{Introduction}

Recent studies indicate that an increased superoxide production by an NAD(P)H oxidase in vascular cells plays an important role in the pathogenesis of acute and chronic vascular dysfunction [1, 2]. In animal studies hypercholesterolemia as well as treatment with angiotensin II induced a marked impairment of NO-dependent vasodilation which was obviously due to a continuously enhanced superoxide production since it could be completely restored by superoxide dismutase (SOD) or nonenzymatic scavengers of superoxide [3]. Therefore it is of great interest to measure superoxide directly in vascular tissues. 
However, established methods to detect superoxide that are applied with great success in studies on neutrophils fail in vascular tissues due to the considerably lower superoxide formation of these cells. In particular, the cytochrome $c$ assay is often not sensitive enough. Alternative assays rely on chemiluminescence (CL) of Cypridina luciferin analogues [4], or the hydroethidine fluorescence technique [5]. Both methods have a low signal to noise ratio that hampers detection especially of the low levels of superoxides in vessels. The widely used chemilumigenic dye lucigenin, on the other hand, has been shown to mediate superoxide formation and there is an ongoing debate on whether lucigenin can be used in vascular cells $[6,7]$. Thus, up to now there has been no appropriate assay available which makes possible the reliable detection of superoxides produced by intact vessels or small amounts of cultured endothelial and smooth muscle cells.

In the present study, we evaluated the applicability of the luminol derivate L-012 [8-amino-5-chloro-7-phenylpyridol[3,4-d]pyridazine-1,4(2H,3H)dione], a newly described and highly sensitive chemilumigenic dye [8], to the measurement of low levels of superoxide formation in endothelial cells and small aortic segments. Since it has been reported that superoxide with vanadate can form a peroxovanadyl complex which easily oxidizes electron donators $[9,10]$, we also evaluated whether the sensitivity of the L-012-CL could be improved by vanadate. We further studied whether this potential effect of vanadate could be separated from the effects of this compound on cellular tyrosine phosphatase activity.

\section{Methods}

\section{Cell Culture}

Human umbilical vein endothelial cells (HUVECs) were isolated from fresh umbilical cords by dispase digestion. They were grown to confluence in standard culture dishes in Medium 199 and supplemented with $16 \%$ fetal calf serum, and $20 \%$ endothelial cell growth medium (PromoCell). Cells from the 1st an 2 nd subpassage were used for the experiments.

\section{Measurement of Superoxide Production in Cell-Free Systems}

L-012-CL. A stock solution of L-012 (0.1 M), dissolved in dimethyl sulfoxide, was further diluted in reaction buffer to a final concentration of $100 \mu M$ immediately prior to the experiments. In CL assays the standard reaction mixture (background) contained $100 \mu M$ xanthine and $100 \mu M$ L-012 in $300 \mu$ phosphate-buffered saline (PBS, $160 \mathrm{~m} M \mathrm{NaCl}, 2.7 \mathrm{~m} M \mathrm{KCl}, 8 \mathrm{~m} M \mathrm{Na}_{2} \mathrm{PHO}_{4}, 1.5 \mathrm{~m} M$ $\mathrm{KH}_{2} \mathrm{PO}_{4}, \mathrm{pH}$ 7.40). The reaction was started by the addition of 1$5 \mathrm{mU} / \mathrm{ml}$ xanthine oxidase (XO) to the standard mixture and the signal intensity recorded with a luminometer (LB 9702, Berthold).
Results are expressed in relative light units per second (RLU/s). In separate experiments, NADH $(100 \mu M)$ was used instead of xanthine to study the NADH/XO-induced superoxide production.

Cytochrome c Assay: The cytochrome c reduction by superoxide was initiated by the addition of XO to the reaction buffer containing NADH $(100 \mu M)$, cytochrome c $(40 \mu M)$ in the presence or absence of SOD $(200 \mathrm{U} / \mathrm{ml})$. The reduction of cytochrome $\mathrm{c}$ was measured by reading the absorbance at $550 \mathrm{~nm}$ (Ultrospec 2000, Pharmacia; SpectraFluor, TECAN). The superoxide-dependent reduction was calculated from the difference of the reduction with or without SOD using the molar extinction coefficient of cytochrome $\mathrm{c}(550 \mathrm{~nm}=$ $\left.21.1 \mathrm{~m}^{-1} \mathrm{~cm}^{-1}\right)$.

\section{Measurement of Superoxide Production in Vascular Cells}

Cultured HUVECs were harvested from cultured dishes using a cell scraper. About $2.0 \times 10^{5}$ intact cells were resuspended in $300 \mu \mathrm{l}$ reaction buffer $\left(135 \mathrm{~m} M \mathrm{NaCl}, 2.7 \mathrm{~m} M \mathrm{KCl}, 1.8 \mathrm{~m} M \mathrm{CaCl}_{2}\right.$, $0.49 \mathrm{~m} M \mathrm{MgCl}_{2}, 0.28 \mathrm{~m} M \mathrm{NaH}_{2} \mathrm{PO}_{4}, 5.5 \mathrm{~m} M$ glucose, $20 \mathrm{~m} M$ HEPES, $\mathrm{pH}$ 7.4) in a standard luminometer reaction vial including $100 \mu M \mathrm{~L}-012$ and incubated for $15 \mathrm{~min}$ at $37.0^{\circ} \mathrm{C}$. The L-012-CL was measured at room temperature after the addition of $1 \mu M$ phorbol 12-myristate 13-acetate (PMA) in the presence or absence of vanadate $(100 \mu M)$. The photon emission was recorded for $15 \mathrm{~min}$ and expressed as integrated light yield (RLU)/mg protein and $15 \mathrm{~min}$. Protein content was determined by the method of Bradford et al. [11].

In separate experiments the superoxide production of intact vessels was studied. The descending thoracic aorta was isolated and removed from adult male Sprague-Dawley rats. In 3-mm aortic ring segments, carefully dissected free of adventitia, the PMA (with or without vanadate)-induced L-012-CL was measured as described above and expressed as RLU/aortic ring. To study the effects of angiotensin II on vascular superoxide formation, the aortic rings were incubated in $300 \mu \mathrm{l}$ reaction buffer in presence or absence of angiotensin II $(100 \mathrm{n} M)$ for $4 \mathrm{~h}$ at $37.0^{\circ} \mathrm{C}$. The superoxide production was determined by L-012 $(100 \mu M)$ immediately after addition of vanadate (or saline) to the aortic rings for $2 \mathrm{~min}$.

\section{Cellular Tyrosine Phosphorylation}

HUVECs were harvested using ice-cold lysis buffer (PBS, 1\% Triton X-100, $1 \mathrm{~m} M$ EDTA, $10 \mu \mathrm{g} / \mathrm{ml}$ leupeptin, $10 \mu \mathrm{g} / \mathrm{ml}$ pepstatin, $10 \mu M$ PMSF, $2 \mathrm{~m} M$ orthovanadate, $100 \mathrm{~m} M \mathrm{NaF}, \mathrm{pH}$ 7.0) and disrupted by passing them 10 times through a 29 -gauge needle. The lysates were centrifuged $(10,000 \mathrm{~g} / 5 \mathrm{~min})$ and the supernatant was used for the experiments. Proteins were separated via SDS-PAGE following standard procedures and transferred onto nitrocellulose membrane. The membrane was probed with phosphotyrosine antibody $(1 \mu \mathrm{g} / \mathrm{ml}$, Upstate) and after incubation with the secondary antibody (Sigma) the membrane was stained with the NBT/BCIP system.

\section{Drugs}

8-Amino-5-chloro-7-phenylpyridol[3,4-d]pyridazine-1,4(2H,3H) dione (L-012) [8] was provided by Dr. K. Schoenafinger (Hoechst Marion Roussel, Frankfurt). Clostridium difficile toxin B was a generous gift from Dr. M. Essler (University of Munich), SOD was purchased from Boehringer Mannheim, endothelial cell growth medium from PromoCell, and orthovanadate from Alexis. All other compounds were purchased from Sigma. 
Statistics

Results are expressed as mean \pm SEM of 3-11 experiments for each condition. Comparison between groups was done using the Wilcoxon signed rank test for paired observations. The differences were considered significant at an error probability level of $<0.05$.

\section{Results}

\section{Detection of Superoxide by L-012-CL in Cell-Free}

Systems

There was an excellent linear correlation between the signal intensity of L-012-CL and the concentration of $\mathrm{XO}$ used (1-5 mU, xanthine $\left.100 \mu M, \mathrm{r}^{2}=0.978\right)$ to generate superoxides. In the presence of $100 \mu M$ xanthine, this corresponds to a range from $130 \pm 1.5$ to $686 \pm 3.9 \mathrm{pmol}$ superoxide/min as measured separately by the cytochrome c assay. Even at a low concentration of $\mathrm{XO}(1 \mathrm{mU}$ corresponding to $130 \pm 1.5 \mathrm{pmol}$ superoxide/min) the L-012-CL revealed an excellent signal to background ratio [signal (mean): 92,092 \pm 5,132 RLU/120s, background (mean): $61 \pm 24 \mathrm{RLU} / 120 \mathrm{~s}$ ]. The L-012-CL was abolished by SOD $(200 \mathrm{U} / \mathrm{ml})$ and the radical scavenger Tiron $(1 \mathrm{~m} M)$ but not affected by the hydroxyl radical scavenger mannitol $(10 \mathrm{~m} M)$ or catalase $(200 \mathrm{U} / \mathrm{ml})$. The specificity of L-012 for superoxide was evaluated in a separate set of experiments (fig. 1). While a low concentration of superoxide (xanthine $100 \mu M$, XO $1 \mathrm{mU} / \mathrm{ml}$ ) markedly increased the L-012-CL very high doses of $\mathrm{H}_{2} \mathrm{O}_{2}(1 \mathrm{mM})$ and $\mathrm{ONOO}^{-}$-donor 3-morpholinosydnonimine (SIN-1, $10 \mu M)$ were required to induce a small augmentation of L-012-CL (fig. 1). The effect of SIN-1 was completely abolished by SOD $(200 \mathrm{U} / \mathrm{ml})$. The NO donor S-nitroso$\mathrm{N}$-acetylpenicillamine (SNAP, $0.1 \mathrm{mM}$ ) did not affect the background signal of L-012.

As shown in figure $2 \mathrm{a}$, the addition of $5 \mathrm{mU} \mathrm{XO}$ to a reaction mixture of NADH $(100 \mu M)$ and L-012 increased the CL by $\sim 5$.4-fold over background CL. A subsequent addition of vanadate $(100 \mu M)$ resulted in a marked augmentation of the signal intensity by a further $\sim 9$-fold, that is $\sim 45$-fold over background CL $(n=4$, fig. $2 \mathrm{a})$. SOD $(200 \mathrm{U} / \mathrm{ml})$ reduced the $\mathrm{L}-012-\mathrm{CL}$ down to the background signal indicating a need for the superoxide for this vanadate-associated amplification (fig. 2a). Figure $2 \mathrm{~b}$ demonstrates that there was a linear correlation between the vanadate-induced L-012 signal and increasing concentrations of $\mathrm{XO}(1-5 \mathrm{mU} / \mathrm{ml})$ with a much higher slope. The addition of vanadate to a reaction mixture of $\mathrm{NADH}+\mathrm{L}-012$ without $\mathrm{XO}$ did not generate a CL signal (fig. 2a). Using the cytochrome c assay [12], we tested

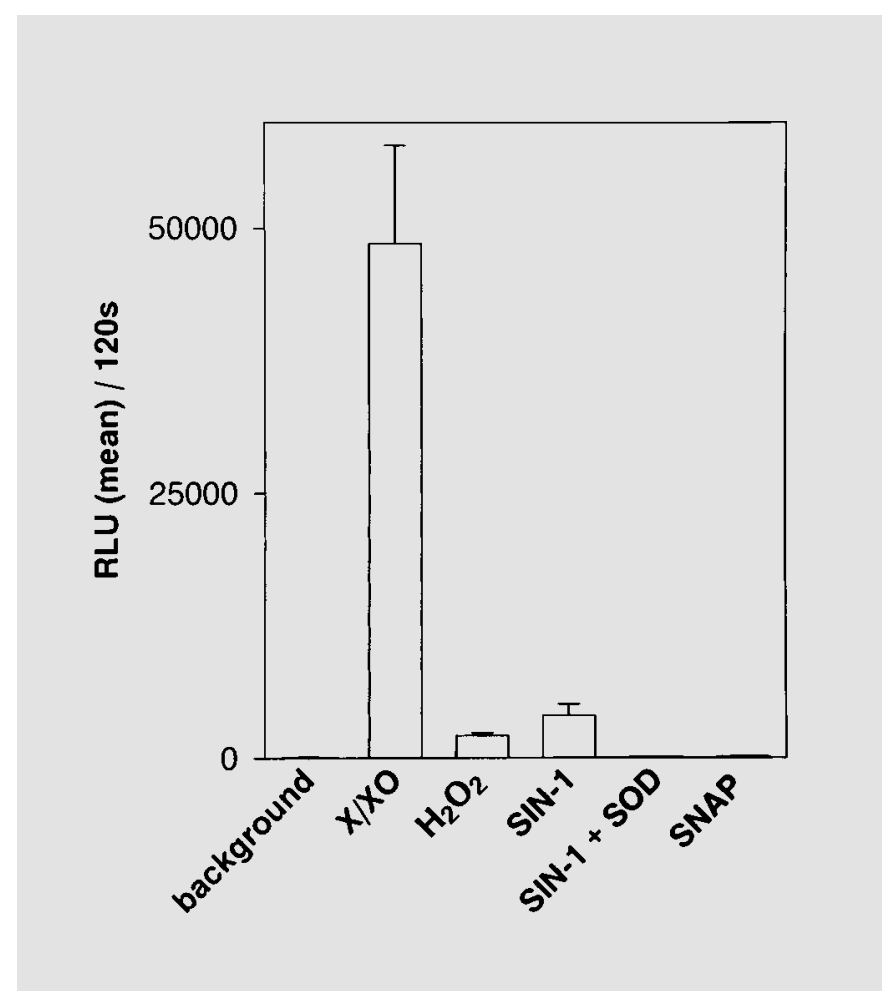

Fig. 1. Specificity of L-012 for superoxide. Low concentrations of superoxide (xanthine $100 \mu M$, XO $1 \mathrm{mU} / \mathrm{ml}$ ) markedly enhanced the L-012 signal. High concentrations of $\mathrm{H}_{2} \mathrm{O}_{2}(1 \mathrm{mM})$ and the ONOOdonor SIN-1 $(10 \mu M)$ induced only a small increase in L-012 signal. The effect of SIN-1 was abolished by SOD $(200 \mathrm{U} / \mathrm{ml})$. The NO donor SNAP $(0.1 \mathrm{mM})$ did not influence the L-012 background signal.

whether L-012 and/or vanadate undergo redox cycling resulting in an artificial superoxide formation. The cytochrome c reduction was not influenced by L-012 (fig. 3a: control; fig. 3b: + L-012). Vanadate $(100 \mu M)$, however, significantly reduced the SOD-inhibitable part of X/XOinduced cytochrome $\mathrm{c}$ reduction (fig. $3 \mathrm{c}$ ). A further addition of L-012 slightly enhanced the inhibitory effect of vanadate (fig. $3 \mathrm{~d}$ ).

\section{Detection of Superoxide in Endothelial Cell Cultures}

by $L-012-C L$

Using the protein kinase $\mathrm{C}$ (PKC) activator PMA as a stimulator for superoxide formation, we examined whether the vanadate-mediated L-012-CL represents an appropriate tool to measure superoxide production by endothelial cells. PMA $(1 \mu M)$ as well as vanadate $(100 \mu M)$ increased the L-012-CL in endothelial cells by 2.8- and 5.1 -fold, respectively $(n=6, p<0.05$, fig. $4 a)$. The PMA- 

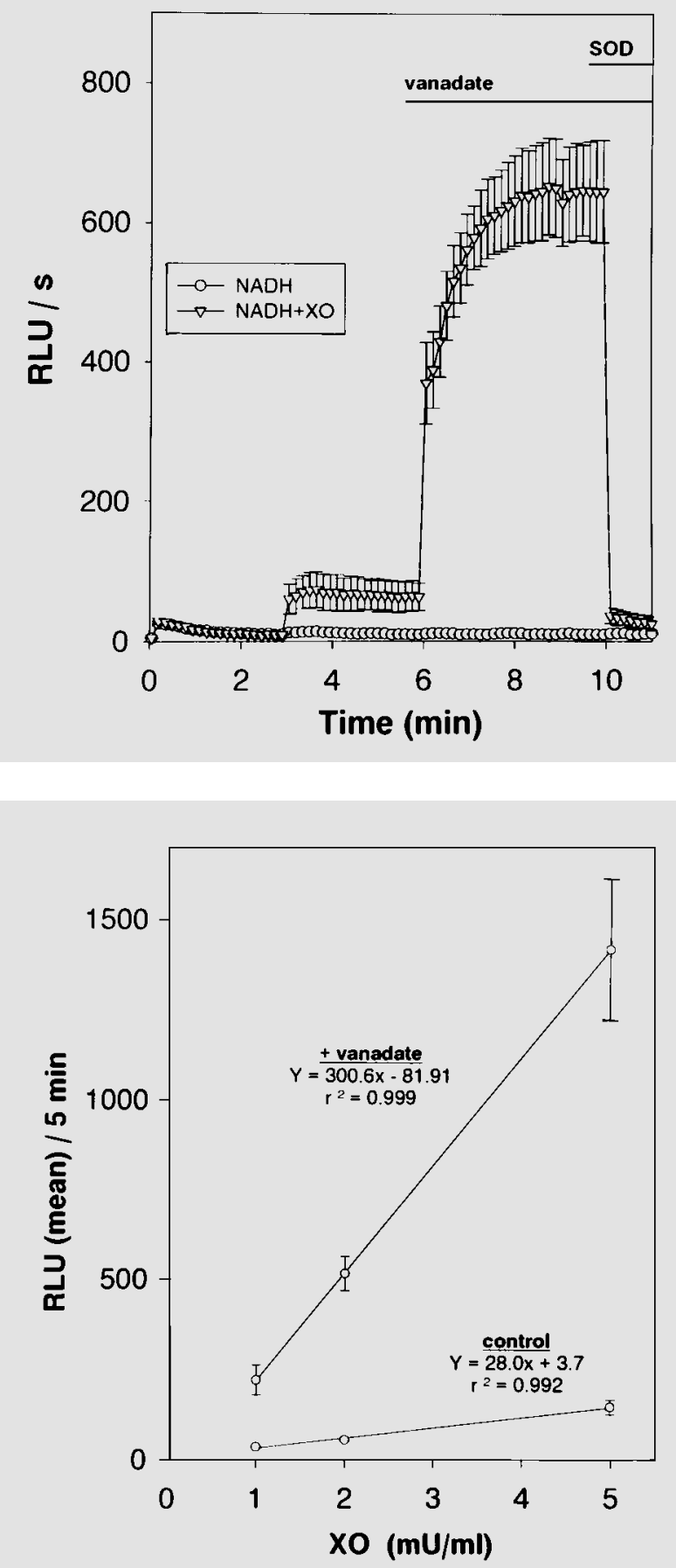

b

Fig. 2. Effect of vanadate on L-012-CL in a cell-free system. a Addition of vanadate $(100 \mathrm{~m} M)$ to the reaction mixture of NADH $(100 \mu M)$ and XO (5 mU) resulted in a marked increase in L-012CL. SOD $(200 \mathrm{U} / \mathrm{ml})$ completely abolished the vanadate-mediated L-012-CL $(n=4)$. b L-012-CL in a superoxide-generating mixture of $\mathrm{NADH}(100 \mu M)$ and $\mathrm{XO}(1-5 \mathrm{mU} / \mathrm{ml})$ with and without additional vanadate $(100 \mu M)$. In both cases, there was a linear correlation but the slope was $\sim 10$-fold higher in the presence of vanadate. Data represent the mean RLU \pm SEM of 3 separate experiments.

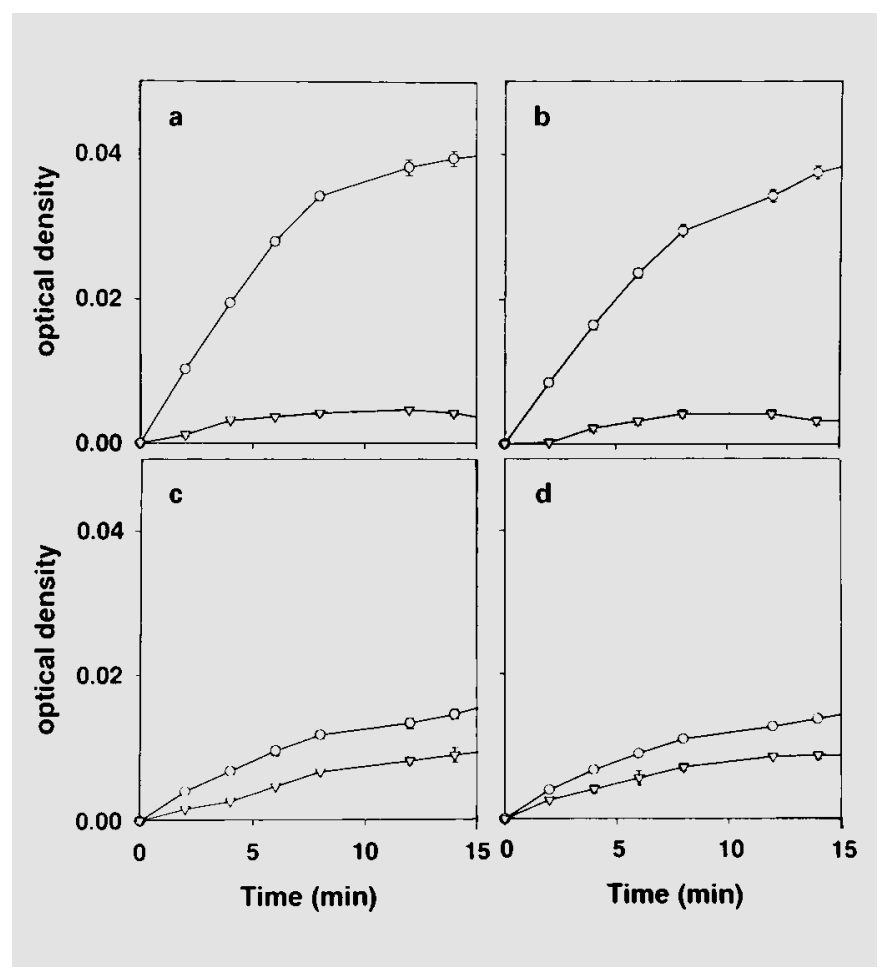

Fig. 3. L-012 did not undergo redox cycling. a In cytochrome c assay the $\mathrm{X} / \mathrm{XO}$-induced (xanthine $100 \mu M$, XO $1 \mathrm{mU} / \mathrm{ml}$ ) superoxide formation was assessed as described in Methods. b Addition of L-012 $(100 \mu M)$ did not affect this reaction. c In the presence of vanadate $(100 \mu M)$ the SOD-dependent part of cytochrome c reduction was significantly attenuated. d L-012 did not affect the vanadatemediated effects on cytochrome c reduction. Data are presented as mean \pm SEM of 4 experiments.

induced L-012-CL was, however, markedly increased by $\sim 17$-fold $\left(4,616 \pm 385\right.$ vs. $277 \pm 61 \times 10^{3} \mathrm{RLU} / 15 \mathrm{~min} /$ $\mathrm{mg}$ protein) in the presence of vanadate (fig. $4 \mathrm{a}, \mathrm{n}=6$ ). SOD $(200 \mathrm{U} / \mathrm{ml})$ as well as the PKC inhibitor staurosporine $(100 \mathrm{n} M)$ nearly abolished this L-012-CL $(\mathrm{p}<0.01$, $\mathrm{n}=5$, fig. $4 \mathrm{a}$ ). As shown in figure $4 \mathrm{~b}$, similar findings were obtained when rat aortic rings were treated with PMA $(1 \mu M)$ and vanadate $(100 \mu M, \mathrm{n}=6)$.

\section{Role of NAD $(P) H$ Oxidase in Endothelial Superoxide Production}

The flavoenzyme inhibitor diphenyleniodoniumchloride (DPI, $30 \mu M$ ) as well as the direct inhibitor of the $\mathrm{NAD}(\mathrm{P}) \mathrm{H}$ oxidase phenylarsine oxide (PAO, $1 \mu M)$ [13] attenuated the PMA/vanadate-induced L-012 signal by 86 and $65 \%$, respectively $(p<0.01, n=6$, fig. 5). Preincubation of the endothelial cells with the $C$. difficile toxin B $(0.5 \mathrm{ng} / \mathrm{ml}$ for $60 \mathrm{~min})$ also attenuated the PMA/vana- 

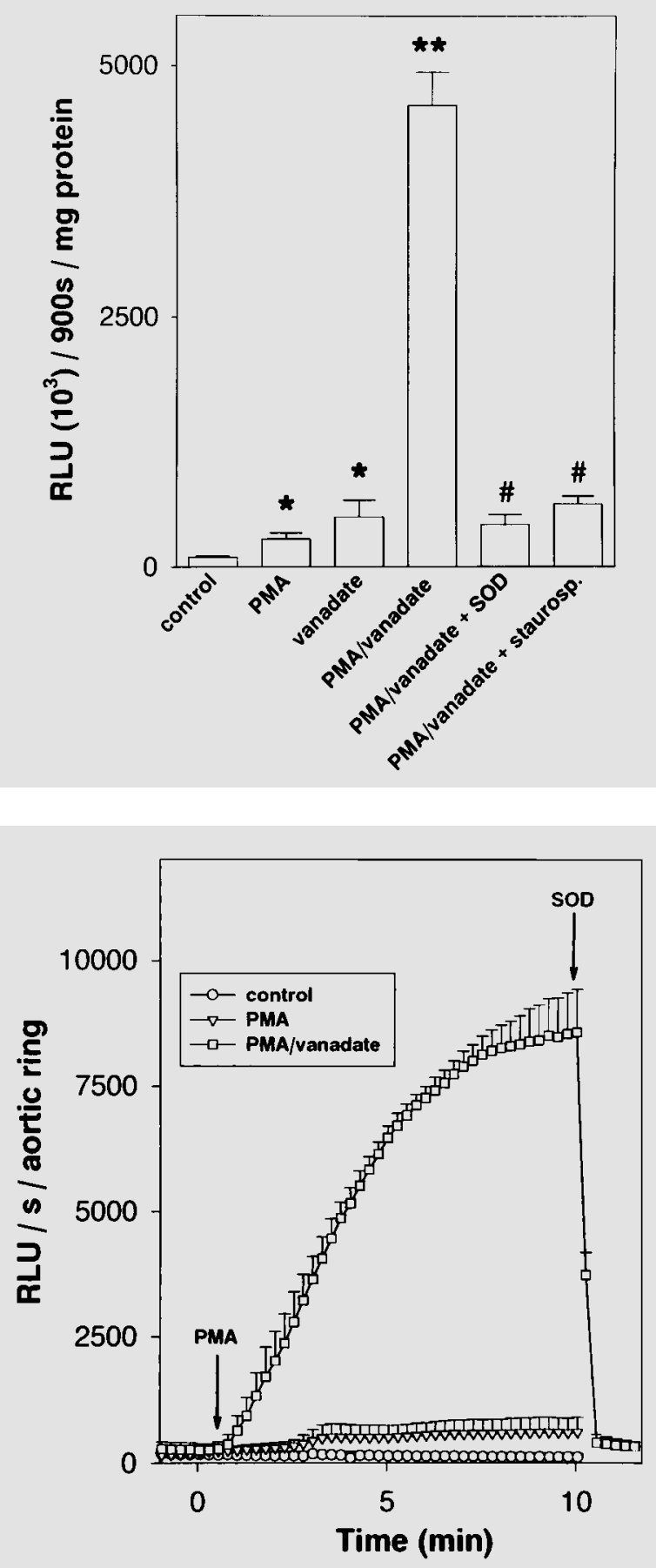

date-induced superoxide formation by $41 \%$ (fig. $5, \mathrm{n}=5$, $\mathrm{p}<0.01)$. The toxin B is known to inactivate Rac1 which is required for full activation of the superoxide-generating NADPH oxidase [14].

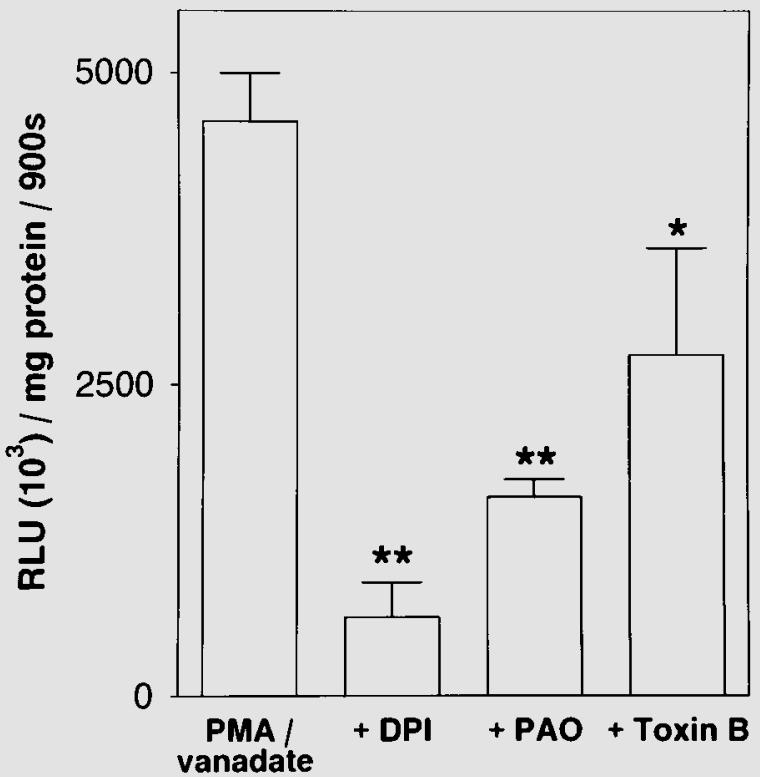

Fig. 4. Effect of vanadate on PMA-induced L-012-CL in vascular cells. a Endothelial cells were treated with PMA $(1 \mu M)$ and /or vanadate $(100 \mu M)$ and the intensity of L-012-CL was measured for $15 \mathrm{~min}$. The combination PMA/vanadate markedly potentiated the L-012-CL which was blocked by preincubation of the cells with either SOD $(200 \mathrm{U} / \mathrm{ml})$ or the PKC inhibitor staurosporine $(100 \mathrm{n} M)$. The data represent the mean \pm SEM of 6 experiments. $* \mathrm{p}<0.05$, ${ }^{* *} \mathrm{p}<$ 0.01 vs. control; ${ }^{\#} \mathrm{p}<0.01$ vs. PMA/vanadate. b In separate experiments, aortic rings from Sprague-Dawley rats were treated with PMA/vanadate as described above $(n=6)$.

Fig. 5. Role of $\mathrm{NAD}(\mathrm{P}) \mathrm{H}$ oxidase in endothelial superoxide production. In PMA $(1 \mu M)$ /vanadate $(100 \mu M)$-stimulated endothelial cells the L-012-CL was assessed in the presence of the NAD(P)H oxidase inhibitors DPI $(30 \mu M)$, or $C$. difficile toxin B $(0.5 \mathrm{ng} / \mathrm{ml})$. Data are presented as mean \pm SEM of $5-6$ separate experiments. ${ }^{*} \mathrm{p}<$ 0.05 vs. control. $* * \mathrm{p}<0.01$ vs. control.

\section{Effect of Vanadate on L-012-CL and Tyrosine Phosphorylation}

Since vanadate acts also as an inhibitor of tyrosine phosphatases we looked whether the augmentation of L-012-CL by vanadate was due to its cellular effects. Incu- 


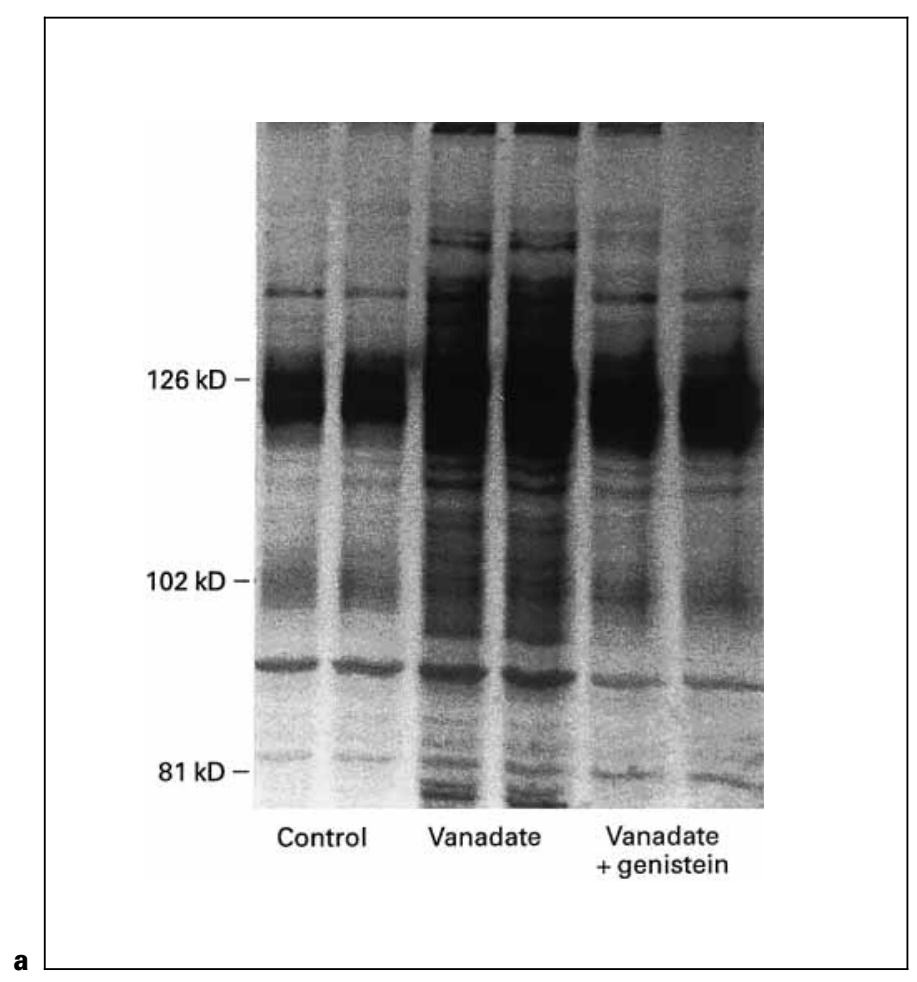

Fig. 6. Effect of vanadate on tyrosine phosphorylation. a Endothelial cells were treated with vanadate $(100 \mu M)$ for $15 \mathrm{~min}$ and the cellular tyrosine phosphorylation was assessed in Western blot analysis. The tyrosine kinase inhibitor genistein $(30 \mu M)$ inhibited the vanadateinduced tyrosine phosphorylation. b Preincubation with genistein $(30 \mu M, \mathrm{n}=11)$ or erbstatin $(1 \mu M, \mathrm{n}=5)$ significantly attenuated the PMA/vanadate-induced L-012-CL in endothelial cells (** $\mathrm{p}<$ 0.01 vs. PMA/vanadate), whereas the inactive analog of genistein daidzein $(30 \mu M, \mathrm{n}=4)$ was ineffective. c Original recordings of L012-CL. Subsequent addition of vanadate to PMA-pretreated endothelial cells immediately enhanced the L-012-CL. Preincubation with genistein $(30 \mu M)$ slightly attenuated the initial increase of L-012-CL but markedly reduced its further increase $(n=3)$.
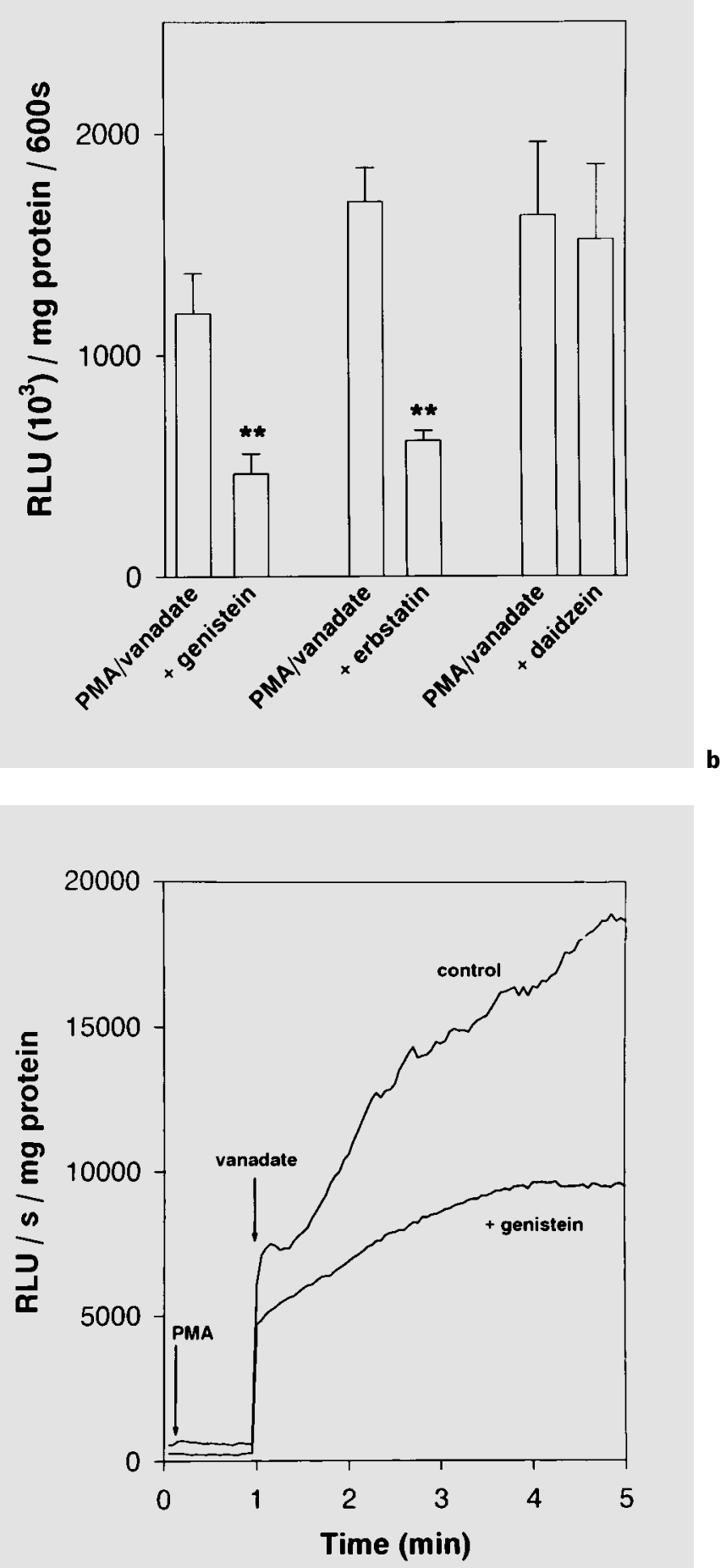


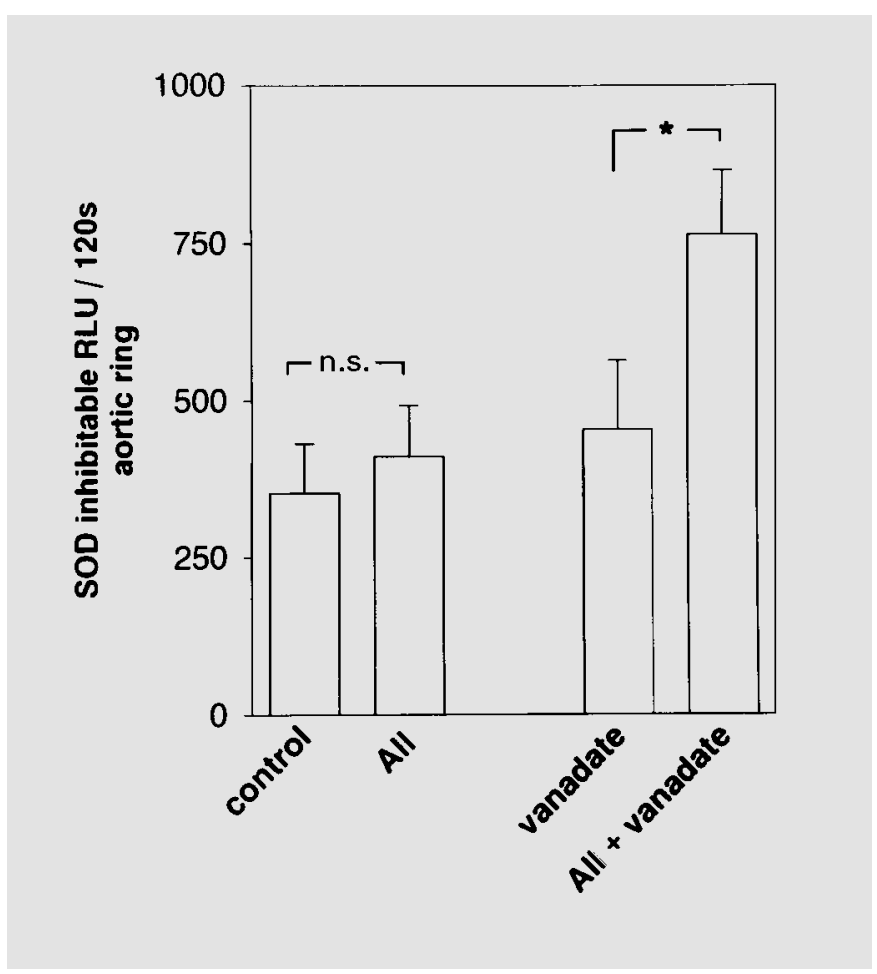

Fig. 7. Angiotensin II-induced superoxide production. Aortic rings prepared from Sprague-Dawley rats were incubated with angiotensin II (AII, $100 \mathrm{n} M$ ) for $4 \mathrm{~h}$ in vitro and the superoxide formation determined using the L-012-CL assay. The SOD-inhibitable portion of the CL signal is depicted. While vanadate $(100 \mu M)$ did not affect signals in control vessels it significantly increased the superoxide-induced L-012-CL in angiotensin II-treated aortic rings $\left(\mathrm{n}=10,{ }^{*} \mathrm{p}<0.05\right)$.

bation with vanadate $(100 \mu M)$ for 15 min enhanced the cellular tyrosine phosphorylation. This was abolished by the tyrosine kinase inhibitor genistein $(30 \mu M$, fig. 6a). Genistein also attenuated the basal as well as the PMA/ vanadate (fig. $6 \mathrm{~b}, \mathrm{n}=11, \mathrm{p}<0.01$ )-induced $\mathrm{L}-012-\mathrm{CL}$ by 26 and $61 \%$, respectively, whereas daidzein $(30 \mu M)$, an inactive analog of genistein, was not effective (fig. $6 \mathrm{~b}, \mathrm{n}=$ 4). Similar results were obtained using erbstatin $(1 \mu M)$, a more potent tyrosine kinase inhibitor (fig. $6 \mathrm{~b}, \mathrm{n}=5$, $\mathrm{p}<$ 0.01 ). To separate tyrosine phosphorylation-mediated effects of vanadate from its direct modulating effects on CL, vanadate was added to endothelial cells after PMA activation. As shown in figure $6 \mathrm{c}$, addition of vanadate increased the L-012-CL rapidly to a new level followed by a further increase at a higher rate. Preincubation of the cells with genistein slightly attenuated the basal as well the initial augmentation of the CL signal but significantly reduced its further increase.

\section{Detection of Angiotensin II-Induced Superoxide}

Production by $L-012-C L$

In freshly isolated rat aortic rings the L-012-CL was quite low (397 $\pm 72 \mathrm{RLU} / 120 \mathrm{~s}, \mathrm{n}=4)$ and was not significantly increased by addition of vanadate $(453 \pm 109$ RLU/120 s, n =4). Addition of SOD reduced the CL signal with and without vanadate to the same background value. This SOD-inhibitable portion of the CL signal is depicted in figure 7. Preincubation of the segments for $4 \mathrm{~h}$ with angiotensin II (100 $\mathrm{n} M)$ did not increase the L-012CL. However, if vanadate was added to angiotensin IIpretreated vessels the CL was significantly higher compared to control vessels (fig. 7, $\mathrm{n}=10, \mathrm{p}<0.01$ ). Vanadate was given immediately before starting measurement in order to exclude an influence of the delayed cellular effects of vanadate. Western blotting showed no change of the tyrosine phosphorylation state within the measuring period of $2 \mathrm{~min}$.

\section{Discussion}

In the present study we used a new chemilumigenic agent, L-012, to measure superoxide formation in cultured endothelial cells and in isolated vessels. In an eosinophilic leukemia cell line, L-012 was compared with luminol and 2-methyl-6-(4-methoxyphenyl)-3,7-dihydroimidazol(1,2-a)pyrazin-3-one (MCLA) showing a 6- to 300fold higher sensitivity to superoxides [8]. We found that, by the addition of vanadate, the detection of superoxides by L-012 can be greatly improved.

In cells and isolated vessels, the augmentation of the L-012 signal by the addition of vanadate has at least two different reasons as reflected by its time course. The immediate increase after addition is similar to what we observed in a cell-free system using NADH/XO as superoxide-generating system. It has been reported that superoxides can form with vanadate a peroxovanadyl complex which easily oxidizes electron donators $[9,10]$. We propose that this peroxovanadyl complex has an important role in the augmentation of the signal since vanadate in the absence of superoxides did not affect the L-012 signal. It has been described before $[9,10,15,16]$ that peroxovanadyl induces a rapid oxidation of $\mathrm{NAD}(\mathrm{P}) \mathrm{H}$. Accordingly, this complex might react faster with L-012 than superoxide alone thus leading to a significantly higher CL signal per unit time. Using the SOD-dependent reduction of cytochrome c, we demonstrate that neither L-012 nor vanadate undergo any redox cycling in contrast to what has been shown for lucigenin [12]. An interaction between 
superoxide and vanadate to form the peroxovanadyl complex with higher affinity than the interaction of superoxide and cytochrome c may also explain why the addition of vanadate attenuated the apparent cytochrome $\mathrm{c}$ reduction in the $\mathrm{X} / \mathrm{XO}$ system. An L-012-dependent redox cycling especially in the endothelial cell supernatant was also very unlikely since the augmenting effect of vanadate was not dependent on the presence of NADH, glucose or HEPES (data not shown), which could serve as additional electron donors being essential for such an autoxidation process $[9,17]$. There was also a linear relationship between the vanadate-enhanced L-012-CL and different concentrations of superoxides, which argues against an additional production of superoxides and allows a quantification of changes in superoxide production. The effect of vanadate was abolished by SOD, suggesting that the presence of the superoxide is essential for this reaction.

In cell-free system L-012 was highly sensitive to superoxides whereas very high concentrations of other radicals were required to induce at least small increases in L-012CL. This was confirmed in PMA/vanadate-stimulated endothelial cells. Scavenging of hydrogen peroxide or hydroxyl radical (by catalase and mannitol, respectively), or inhibition of NO synthase did not significantly influence the L-012-CL (data not shown), whereas SOD abolished the signal.

It should, however, be noted that vanadate also acts as an inhibitor of cellular tyrosine phosphatases [18]. In the cell supernatant addition of vanadate led to a delayed further increase of the L-012-CL after a short initial plateau phase had been reached. Accordingly, the tyrosine kinase inhibitor genistein significantly attenuated the PMA/vanadate-induced L-012-CL in endothelial cells while it did not influence the L-012-CL in the cell-free X/XO system (data not shown). In the present study, it was further excluded that genistein simply acted as a superoxide scavenger [19]. While its inactive analog daidzein did not affect the L-012-CL, the alternative tyrosine kinase inhibitor erbstatin significantly reduced the signal. These results suggest that a prolonged exposure to vanadate further increases the CL signal by a true augmentation of the cellular superoxide formation by inhibition of tyrosine phosphatases. Such an enhancing effect of vanadate on superoxide production by neutrophils has been shown before with independent superoxide detection asssays $[20,21]$. The finding that tyrosine phosphorylationdependent steps play an important role in endothelial superoxide formation is in agreement with a role for the neutrophil-type $\mathrm{NAD}(\mathrm{P}) \mathrm{H}$ oxidase. Moreover, three independent inhibitors of a neutrophil-type $\mathrm{NAD}(\mathrm{P}) \mathrm{H}$ oxi- dase, DPI, PAO and toxin B [13, 14, 22], attenuated vanadate-promoted endothelial superoxide formation. Since it is known that DPI also can inhibit XO [23], and PAO act as a nonspecific thiol oxidant we further tested the effects of toxin B which inactivates Rac1 [14]. The latter is known to be necessary for full activation of the NAD(P)H oxidase. Western blotting of tyrosine phosphorylation in cultured endothelial cells as well as the time course of the L-012 signal after addition of vanadate show, however, that at least in the first 2 min tyrosine phosphorylationdependent superoxide production does not affect the superoxide measurement in endothelial cells or isolated vessels.

L-012 has been shown to be more sensitive than MCLA and luminol [8]. In fact, we could detect reasonably well the superoxide production of small vessel segments and of a relatively small amount $\left(\sim 2.0 \times 10^{5}\right.$ cells $)$ of endothelial cells. It was not possible, however, to detect increases induced by the physiologic stimulus angiotensin II with L-012 alone. Only in the presence of vanadate there was a sufficient signal to noise ratio of L-012 in the low (patho)physiologic range of superoxide production. This is of particular importance in isolated vessel segments which had a much lower absolute superoxide formation than the cultured cells. It should be emphasized that L-012 obviously detects only extracellular superoxides since the CL could be completely blocked by SOD which cannot pass the cell membrane. Such relatively modest increases of superoxides as obtained with the sensitive L-012/vanadate combination seem, however, to be of high pathophysiologic relevance being the reason for endothelial dysfunction. This method may therefore be very useful to study the regulation and pathophysiologic alterations of superoxide production in vascular cells.

\section{Acknowledgments}

This study was supported by the Deutsche Forschungsgemeinschaft (SFB 553 Teilprojekt B2). H.-Y. Sohn was a fellow of the German Cardiac Society. 


\section{References}

1 Rajagopalan S, Kurz S, Münzel T, Tarpey M, Freeman BA, Griendling KK, Harrison DG: Angiotensin II-mediated hypertension in the rat increases vascular superoxide production via membrane NADH/NADPH oxidase activation. Contribution to alterations of vasomotor tone. J Clin Invest 1996;97:1916-1923.

2 Warnholtz A, Nickenig G, Schulz E, Macharzina R, Brasen JH, Skatchkov M, Heitzer T, Stasch JP, Griendling KK, Harrison DG, Bohm M, Meinertz T, Münzel T: Increased NADH-oxidase-mediated superoxide production in the early stages of atherosclerosis: Evidence for involvement of the renin-angiotensin system. Circulation 1999;99:2027-2033.

3 Laursen JB, Rajagopalan S, Galis Z, Tarpey M, Freeman BA, Harrison DG: Role of superoxide in angiotensin II-induced but not catecholamine-induced hypertension. Circulation 1997;95:588-593.

4 Nakano M: Determination of superoxide radical and singlet oxygen based on chemiluminescence of luciferin analogs. Methods Enzymol 1990;186:585-591.

5 Bindokas VP, Jordan J, Lee CC, Miller RJ: Superoxide production in rat hippocampal neurons: Selective imaging with hydroethidine. J Neurosci 1996;16:1324-1336.

6 Vasquez VJ, Hogg N, Pritchard KAJ, Martasek P, Kalyanaraman B: Superoxide anion formation from lucigenin: An electron spin resonance spin-trapping study. FEBS Lett 1997;403:127130.

7 Tarpey MM, White CR, Suarez E, Richardson G, Radi R, Freeman BA: Chemiluminescent detection of oxidants in vascular tissue: Lucigenin but not coelenterazine enhances superoxide formation. Circ Res 1999;84:1203-1211.
8 Nishinaka Y, Aramaki Y, Yoshida H, Masuya $\mathrm{H}$, Sugawara T, Ichimori Y: A new sensitive chemiluminescence probe, L-012, for measuring the production of superoxide anion by cells. Biochem Biophys Res Commun 1993;193: 554-559.

9 Liochev SI, Fridovich I: Vanadate-stimulated oxidation of $\mathrm{NAD}(\mathrm{P}) \mathrm{H}$ in the presence of biological membranes and other sources of $\mathrm{O}_{2}^{-}$. Arch Biochem 1990;279:1-7.

10 Liochev SI, Fridovich I: Vanadate-stimulated oxidation of NAD(P)H. Free Radic Biol Med 1989;6:617-622.

11 Bradford MM: A rapid and sensitive method for the quantitation of microgram quantities of protein utilizing the principle of protein-dyebinding. Anal Biochem 1976;72:248-254.

12 Liochev SI, Fridovich I: Lucigenin as mediator of superoxide production: Revisited. Free Radic Biol Med 1998;25:926-928.

13 Le Cabec V, Maridonneau PI: Complete and reversible inhibition of NADPH oxidase in human neutrophils by phenylarsine oxide at a step distal to membrane translocation of the enzyme subunits. J Biol Chem 1995;270:20672073.

14 Sehr P, Joseph G, Genth H, Just I, Pick E, Aktories K: Glucosylation and ADP ribosylation of rho proteins: Effects on nucleotide binding, GTPase activity, and effector coupling. Biochemistry 1998:37:5296-5304.

15 Liochev S, Ivancheva E, Fridovich I: Effects of vanadate on the oxidation of NADH by xanthine oxidase. Arch Biochem Biophys 1989; 269:188-193.
16 Liochev S, Fridovich I: Superoxide is responsible for the vanadate stimulation of NAD(P)H oxidation by biological membranes. Arch Biochem Biophys 1988;263:299-304.

17 Liochev S, Fridovich I: The oxidation of NADH by vanadate plus sugars. Biochim Biophys Acta 1987;924:319-322.

18 Fleming I, Bara AT, Busse R: Calcium signalling and autacoid production in endothelial cells are modulated by changes in tyrosine kinase and phosphatase activity. J Vasc Res 1996;33:225-234.

19 Wei H, Cai Q, Rahn RO: Inhibition of UVlight- and Fenton reaction-induced oxidative DNA damage by the soybean isoflavone genistein. Carcinogenesis 1996;17:73-77.

20 Zor U, Ferber E, Gergely P, Szucs K, Dombradi V, Goldman R: Reactive oxygen species mediate phorbol ester-regulated tyrosine phosphorylation and phospholipase A2 activation: Potentiation by vanadate. Biochem J 1993; 295;879-888.

21 Goldman R, Zor U: Activation of macrophage PtdIns-PLC by phorbol ester and vanadate: Involvement of reactive oxygen species and tyrosine phosphorylation. Biochem Biophys Res Commun 1994;199:334-338.

22 Doussiere J, Vignais PV: Diphenylene iodonium as an inhibitor of the NADPH oxidase complex of bovine neutrophils. Factors controlling the inhibitory potency of diphenylene iodonium in a cell-free system of oxidase activation. Eur J Biochem 1992;208:61-71.

23 Sanders SA, Eisenthal R, Harrison R: NADH oxidase activity of human xanthine oxidoreductase - generation of superoxide anion. Eur J Biochem 1997;245:541-548. 